\title{
Farmazia-zerbitzu profesional asistentzialak Euskal Autonomia Erkidegoko (EAE) farmazietan
}

\author{
(Professional Pharmaceutical Care Services \\ in the pharmacies of Basque Country)
}

\author{
Xabier Aizpurua-Arruti ${ }^{1,2}$, Arantxa Isla ${ }^{1}$, María Ángeles Solinís ${ }^{1}$, Begoña Calvo ${ }^{1}$, \\ Ana del Pozo-Rodríguez*1, Estibaliz Goyenechea ${ }^{2}$ \\ ${ }^{1}$ Farmakozinetika, Nanoteknologia eta Terapia Genikoa taldea (PharmaNanoGene), \\ Farmazia Fakultatea (UPV/EHU), Vitoria-Gasteiz \\ ${ }^{2}$ Gipuzkoako Sendagaigileen Elkartea (GSE), Donostia-San Sebastián
}

\begin{abstract}
LABURPENA: Historian zehar, farmaziak eraldaketa handiak izan ditu. Aurretik, farmaziak sendagaien prestaketa eta dispentsazioa zituen oinarri nagusitzat, baina, gizartearen aldaketa dela eta, lanbide horrek bide asistentzialagoa hartu du. Horrela, azken hamarkadetan arreta farmazeutikoaren eta farmazia asistentzialaren garapena sustatu da. Arreta farmazeutikoa pazientearen beharrak artatzeko farmazialariaren praktika profesional gisa defini daiteke, sendagaiekin loturiko arazoak modu jarraituan, sistematizatuan eta dokumentatuan detektatuz, prebenituz eta konponduz, pazientearekiko berarekiko eta osasun-taldeko gainerako profesionalekiko lankidetzan, pazientearen bizi-kalitatea hobetuko duten emaitza zehatzak lortzeko. Arreta farmazeutikoarekin eta farmazia asistentzialarekin lotuak, Farmazia-Zerbitzu Profesional Asistentzialak (FZPAk) sortu dira; farmazia komunitarioak herritar guztiei zerbitzu aukera zabala eskaintzen die. Gaur egun, munduko ia herrialde guztietan zerbitzu berriak diseinatzen eta ezartzen ari dira, eta, aldi berean, farmazia komunitarioaren jardueran txertatu nahi dira. FZPAk bi taldetan sailkatzen dira. Alde batetik, Arreta Farmazeutikoaren Zerbitzuak eta, beste alde batetik, Komunitateko Osasunarekin erlazionaturiko Zerbitzuak. Duela urte batzuk, eta Euskal Autonomia Erkidegoko (EAE) Farmazialarien Kontseiluarekin bat eginez, EAEko farmaziak FZPAk eskaintzen hasi ziren. Zerbitzu horiek, lanbidearen aldaketarako tresna garrantzitsua izanik, pazienteei ez ezik, farmazialarien kolektiboari eta farmazialariei eurei ere onurak ekartzen dizkiete. Hala ere, farmazia asistentziala sustatzeko erronka garrantzitsua da pazienteek eta gainerako osasun-profesionalek farmazialarien esku-hartze kliniko horien onurak ezagutzea, eta, farmazia komunitarioa, osasun-sistema publikoetan era sakonago batean integratzea.
\end{abstract}

HITZ GAKOAK: farmazia-zerbitzu profesional asistentzialak (FZPAk), arreta farmazeutikoa, farmazia asistentziala, sendagaiekin erlazionaturiko arazoak (SEAk), sendagaiekin erlazionaturiko emaitza negatiboak (SENak).

\begin{abstract}
Throughout history, the pharmacy has undergone major transformations. Previously, pharmacy was based on the preparation and dispensing of medicines, but due to the changes in society, the pharmaceutical profession has taken a more care path. Thus, in recent decades the development of pharmaceutical care and healthcare pharmacy has been prompted. Pharmaceutical care can be defined as the pharmacist's professional practice of caring for the patient's needs by detecting, preventing, and resolving drug-related problems in a continuous, systematic, and documented manner, in collaboration with the patient and other health care professionals to achieve accurate patient quality of life. Related to pharmaceutical care and healthcare pharmacy, Professional Pharmaceutical Care Services (PPCS) have been developed; so that community pharmacies offer a wide range of services to all citizens. Nowadays, in almost every country in the world, new services are being designing and implementing with the aim to also integrate them into the activity of community pharmacy. PPCSs fall currently into two groups. On the one hand, the Pharmaceutical Care Services and on the other hand, the Services related to Community Health. A few years ago, and in conjunction with the Basque Pharmacists' Council, Basque pharmacies began offering PPCSs. These services, as important tools for change in the profession, do not only benefit patients, but also the collective of pharmacists and pharmacists themselves. However, an important challenge in promoting healthcare pharmacy is to make patients and other health professionals aware of the benefits of such clinical interventions, and thus to integrate community pharmacy into public health systems.
\end{abstract}

KEYWORDS: Professional Pharmaceutical Care Services (PPCS), Pharmaceutical Care, Healthcare Pharmacy, Drug-Related Problems (DRPs), Negative Results associated with Medication (NRMs).

* Harremanetan jartzeko / Corresponding author: Ana del Pozo-Rodríguez. Farmakozinetika, Nanoteknologia eta Terapia Genikoa taldea (PharmaNanoGene), Farmazia Fakultatea (UPV/EHU), Unibertsitateko pasabidea, 7 (01006 Vitoria-Gasteiz)). ana.delpozo@ehu.eus - https://orcid.org/0000-0003-2478-0884.

Nola aipatu / How to cite: Aizpurua-Arruti, Xabier; Isla, Arantxa; Solinís, María Ángeles; Calvo, Begoña; Del Pozo-Rodríguez, Ana; Goyenechea, Estibaliz (2021). "Farmazia-zerbitzu profesional asistentzialak Euskal Autonomia Erkidegoko (EAE) farmazietan»; Ekaia, 39, 2021, 131-152. (https://doi.org/10.1387/ekaia.21863).

Jasoa: 2020, ekainak 29; Onartua: 2020, abuztuak 27.

ISSN 0214-9001 - elSSN 2444-3255 / (C) 2021 UPV/EHU

(c) (i) Obra hau Creative Commons Atribución 4.0 Internacional-en

lizentziapean dago 
Xabier Aizpurua-Arruti, Arantxa Isla, María Ángeles Solinís, Begoña Calvo, Ana del Pozo-Rodríguez, Estibaliz Goyenechea

\section{SARRERA}

Historian zehar, farmaziak eraldaketa handiak izan ditu. Azken hamarkadetan egin diren aurrerapenen artean, arreta farmazeutikoaren sorrera eta farmazia asistentzialaren sustatzea izan dira eboluzio garrantzitsuenekoak. Kontzeptu berri horiek farmazia tradizionalaren eboluzioaren ondorioz sortu ziren. Aurretik, farmaziak sendagaien prestaketa eta dispentsazioa zituen oinarri, baina gizartearen aldaketa eta medikazioa hobeto maneiatzeko beharra direla eta, lanbide horrek bide asistentzialagoa hartu du. Izan ere, gaur egun, farmazia komunitarioaren jarduera pazientearengan ardazten da, batez ere [1]. Farmazialariek eskainitako zerbitzuek eta egindako interbentzio klinikoek medikamentuen aurkako gertaerak murriztu ditzaketela eta pazientearen emaitza klinikoak eta humanistikoak hobetu ditzaketela frogatu da [2].

Arreta farmazeutiko kontzeptua ez da berria. Estatu Batuetan, adibidez, 1980. urte inguruan ageri zen lehen aldiz [1]. Australian eta Zeelanda Berrian, bestalde, farmazia-lanbidea 1990. urte inguruan hasi zen arreta pazientean jartzen, bere jardueraren ardatz nagusi gisa, medikamentua izan beharrean [3]. Arreta farmazeutikoaren lehenengo definizioa, Heplerrek eta Strandek eman zuten: «Arreta farmazeutikoa farmakoterapiaren hornidura arduratsua da, paziente bakoitzaren bizi-kalitatea hobetuko duten emaitza zehatzak lortzeko» [4].

Garai horretan, Estatu Batuetan arreta farmazeutikoaren beharra nabarmendu zen, eta, 1992an, arreta farmazeutikoaren eredu praktiko global bat diseinatu zen, Minnesota Proiektua izenekoa. Proiektu hori inspirazioiturri izan zen zenbait herrialdetan arreta farmazeutikoarekin erlazionatutako beste programa batzuk martxan jartzeko; Espainian, esaterako, tratamendu farmakologikoaren jarraipenaren DADER izeneko programa jarri zen abian [5]. Urte askoan, DADER programa erreferentziazko programa izan da Espainiako Estatuan, arreta farmazeutikoko beste programa batzuk abian jartzeko.

Osasunaren Mundu Erakundeak (OME), 1993. urtean farmazialariaren erantzukizunak bateratu zituen, eta adierazpena hauek egin zituen: $\ll P a-$ zientea da farmazialariaren ekintzen onuradun nagusia, eta arreta farmazeutikoa farmazialariaren jarreren, portaeren, konpromisoen, kezken, balio etikoen, funtzioen, ezagutzen, erantzukizunen eta trebetasunen multzoa $d a$, eta pazientearen osasunean eta bizi-kalitatean zehaztutako emaitza terapeutikoak lortzea du helburu» [6]. Hortik aurrera, arreta farmazeutikoa Europa mailan zabaldu zen, eta ekimenak bultzatu ziren hainbat herrialdetan eraldaketa horretan lanean hasteko [7].

Euskal Autonomia Erkidegoak (EAEk), farmazia-antolamenduari buruzko 11/1994 Legean, arreta farmazeutikoa horrela definitu zuen: «Arreta 
farmazeutikoa interes publikoko zerbitzu gisa hartzen da, eta jarduera guztiak biltzen ditu, bai laguntzaren arloan, bai osasun publikoaren arloan. Jarduera horiek, indarrean dagoen legerian ezarritako baldintzetan, profesional sanitarioek eman behar dituzte, farmazialari baten ardurapean, farmazia-establezimendu eta zerbitzuetan» [8].

Estatu mailan, 2001. urtean, Osasun eta Kontsumo Ministerioak arreta farmazeutikoari buruzko kontsentsua argitaratu zuen, herritarren bizi-kalitatea hobetzen laguntzeko. Adostasun horren arabera, arreta farmazeutikoa pazientearen beharrak artatzeko farmazialariaren praktika profesional gisa defini daiteke, sendagaiekin loturiko arazoak (SEAk) modu jarraituan, sistematizatuan eta dokumentatuan detektatuz, prebenituz eta konponduz, pazientearekiko berarekiko eta osasun-taldeko gainerako profesionalekiko lankidetzan, pazientearen bizi-kalitatea hobetuko duten emaitza zehatzak lortzeko [9].

Arreta farmazeutikoko zerbitzuen praktika-eredu bat garatzeko eta arreta farmazeutikoa estatu mailan orokortzeko [10], 2004. urtean, Arreta Farmazeutikoko Foroa sortu zen (Foro), lantalde gisa antolatuta. Talde horrek egindako lanaren ondorioz, adostasun-dokumentua argitaratu zen 2008. urtean, terminologian, ezagutza orokorretan eta arreta farmazeutikoko zerbitzuen praktikan hartutako erabakiak errazteko.

Une horretatik aurrera, farmazia komunitarioari lotutako erakundeek beharrezkotzat jo zuten Foroak ezarritako gidalerroak lantzen jarraitzea, eta, horrela, Arreta Farmazeutikoko Foroa Farmazia Komunitarioan (AF-FC Foroa) izeneko talde berri bat eratu zen. Gaur egun, Farmazialarien Elkargo Ofizialen Kontseilu Nagusiak (CGCOF), Pharmaceutical Care España fundazioak, farmazia komunitarioen Espainiako gizarte zientifikoak (SEFACek), Granadako Unibertsitateko Arreta Farmazeutikoko Ikerketa Taldeak eta Dekanoen Biltzar Nazionalak osatzen dute lantalde hori. Erreferentzia-agentea da arreta farmazeutikoaren arloan, eta urte hauetan zehar argitaratu dituzten eskuliburuak kontsulta-iturri ohikoak izan dira farmazia-lanbiderako, estatu-mailan [11]. AF-FC Foroak, farmazia-zerbitzu profesional asistentzialak (FZPAk) farmazia komunitarioan ezartzen laguntzea du helburu eta, horrela, egungo farmazia komunitarioan, etorkizun profesional berri baterako oinarriak presta ditzake, sendagaiak eta osasunproduktuak erabiltzen dituen edo behar dituen pazienteari arreta osoa emateko [12].

Honekin batera, gaur egungo gizartean, aldaketa nabarmenak gertatzen ari dira hainbat arlotan, eta osasuna ez da salbuespen bat. Pertsonak gero eta arduratuago daude ongizatea lortzeaz eta osasunaren kontzeptuarekin lotutako alderdi guztiei buruzko askotariko informazioa jasotzen dute. Aldi berean, paziente-profil berezi baten garrantzia handitzen ari da; paziente adindu kroniko polimedikatuena, hain zuzen ere. Farmazia ere ego- 
Xabier Aizpurua-Arruti, Arantxa Isla, María Ángeles Solinís, Begoña Calvo, Ana del Pozo-Rodríguez, Estibaliz Goyenechea

kitzapen-prozesu batean murgildua dago, pazienteen beharretara eta osasun-sistemaren aldaketetara moldatzeko. Beraz, farmazia asistentzialerantz eboluzionatzen da. Farmazialaria, sendagaien hornitzailea izateaz gain, pazientean gero eta zentratuago dagoen profesionala da.

\section{FARMAZIA-ZERBITZU PROFESIONAL ASISTENTZIALAK (FZPAk). KONTZEPTUA ETA SAILKAPENA}

AF-FC Foroak honela definitu ditu FZPAk: Farmazia komunitarioko farmazialari batek bere gaitasun profesionalak erabiliz egindako osasunjarduerak dira, gaixotasunak prebenitzeko eta biztanleriaren osasuna eta medikamentu zein osasun-produktuen erabiltzaileen osasuna hobetzeko asmoz. Horretarako, farmazialariak aktiboki egingo du bere zeregina tratamenduen erabilera-prozesuen emaitzen optimizazioa lortzeko. Jarduera horiek osasun-sistemaren helburu orokorrekin bateratuta egongo dira eta entitate propioa izango dute; hau da, definizio, helburu, prozedura eta dokumentazio-sistema konkretuak izango dituzte. Horrela, zerbitzuen ebaluazioa eta ordainsaria ziurtatuko dira, aldi berean, unibertsaltasuna, iraunkortasuna eta jasangarritasuna bermatuz [13].

FZPAen bitartez, farmazia komunitarioak aktibitate asistentzial zabala eskain diezaioke gizarteari. Farmazialarien Nazioarteko Federazioak eta OMEk, 2006an, dokumentu bateratu batean adierazi zuten ez dutela etorkizunik dispentsazioan soilik oinarritutako farmazia komunitarioek [14]. Gaur egun, munduko ia herrialde guztietan zerbitzu berriak diseinatzen eta ezartzen ari dira, eta, aldi berean, farmazia komunitarioaren jardueran txertatu nahi dira. Espainian, adibidez, CGCOFak Hazfarma izeneko proiektu bat sortu zuen 2014. urtean [15], farmazia komunitarioan zerbitzu profesional farmazeutikoak garatzeko.

Hala ere, garrantzizkoa da jakitea farmazian egiten diren zerbitzu guztiak ez direla FZPAk, nahiz eta osasuna eta bizi-kalitatea hobetzearekin zerikusia duten. FZPAek 1. taulako irizpideak bete behar dituzte, eta zerbitzu horiek egiteko farmazialariek zerbitzu bakoitzerako akreditazioa lortu behar dute [13].

FZPAen artean, dispentsazioa, indikazioa eta jarraipen farmakoterapeutikoa (JFT) hartu ziren, hasiera batean, arreta farmazeutikoan, oinarrizkotzat. Hala ere, 2019an AF-FC Foroak aurkeztutako gida praktikoan, beste bi zerbitzu gehitu ziren: medikazioaren kontziliazioa eta atxikidura terapeutikoa. Gida horren helburu nagusietako bat terminologia eta prozedura estandarizatuak ezartzea da, farmazia komunitarioan FZPAk egiten dituzten farmazialariek aplika ditzaten, behar duten paziente guztiei osasun-laguntza homogeneoa bermatuz. 
1. taula. FZPAk egiaztatzeko irizpideak.

1. Farmazialariak egiten du, edo farmazialari baten ardurapean egiten da?

2. Farmazialari komunitarioaren eskumena da?

3. Gaixotasuna prebenitzeko balio du?

4. Biztanleriaren osasuna hobetzeko erabilgarria da?

5. Medikamentuen edo osasun-produktuen erabiltzaileen osasuna hobetzeko balio du?

6. Farmazialariak modu aktiboan lan egiten du tratamenduen erabilera-prozesu edota emaitzetan?

7. Osasun-sistemaren helburu orokorrekin lerrokatutako jarduera da?

8. Bere ebaluazioa eta ordainsaria bermatzea ahalbidetzen duen entitate propioa (definizioa, helburua, prozedura eta dokumentazio-sistema) du?

9. Unibertsaltasun, jarraipen eta jasangarritasun ezaugarriak betetzen al ditu?

1., 2., 3., 8., 9. eta 10. galderen erantzunek baiezkoak izan behar dute, eta 4., 5., 6. eta

7. erantzunetatik gutxienez batek, FZPA izateko.

Gaur egun, FZPAk bi taldetan sailkatzen dira (1. irudia). Alde batetik, arreta farmazeutikoaren zerbitzuak eta, beste alde batetik, komunitateko osasunarekin erlazionaturiko zerbitzuak [13]. Sailkapen horretan agertzen den zerrenda ez da itxia eta baztertzailea, eta FZPA kopuruak ere gora egitea espero da farmazia asistentzialak aurrera egin ahala. 


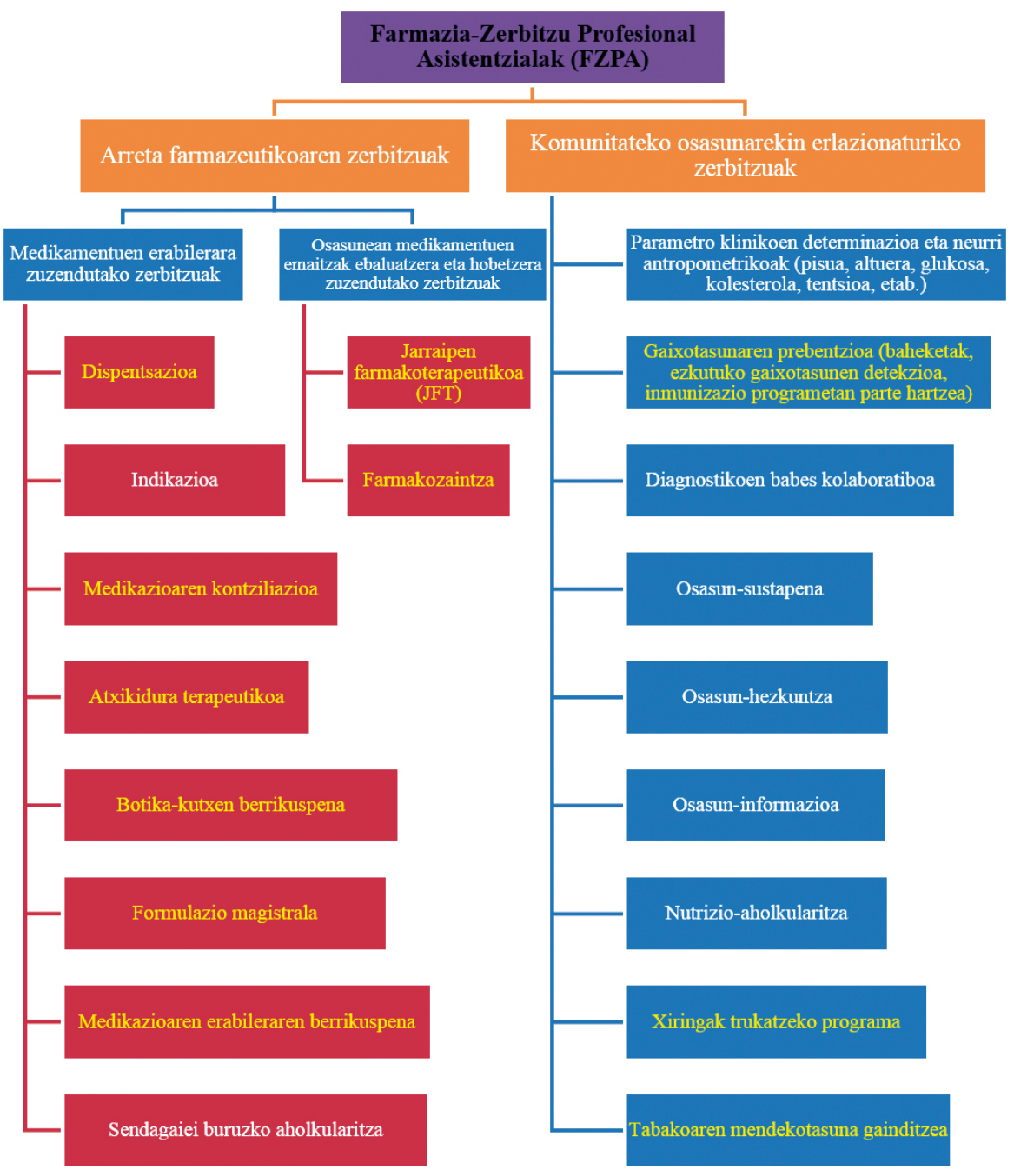

1. irudia. FZPAen sailkapena AF-FC Foroaren arabera. Horiz markatutako zerbitzuak EAEko farmazietan programa baten barnean ezarriak diren zerbitzuak dira; zuriz markatutakoak, programa finkorik izan ez duten baina ezar litezkeen zerbitzuak.

\subsection{Arreta farmazeutikoaren zerbitzuak}

Arreta Farmazeutikoari dagokionez, haren helburu nagusia SEAk detektatzea da, sendagaiekin erlazionaturiko emaitza negatiboak (SENak) saihesteko eta ebazteko. Bigarren irudian ikus daitezke AF-FC Foroak 
prestatutako SEAen zerrenda eta horiek eragin ditzaketen SENak. Esparru horretan eskain daitezkeen zerbitzuak 2 taldetan banatzen dira: medikamentuen erabilerara zuzendutako zerbitzuak eta osasunean medikamentuen emaitzak ebaluatzera eta hobetzera zuzendutako zerbitzuak.

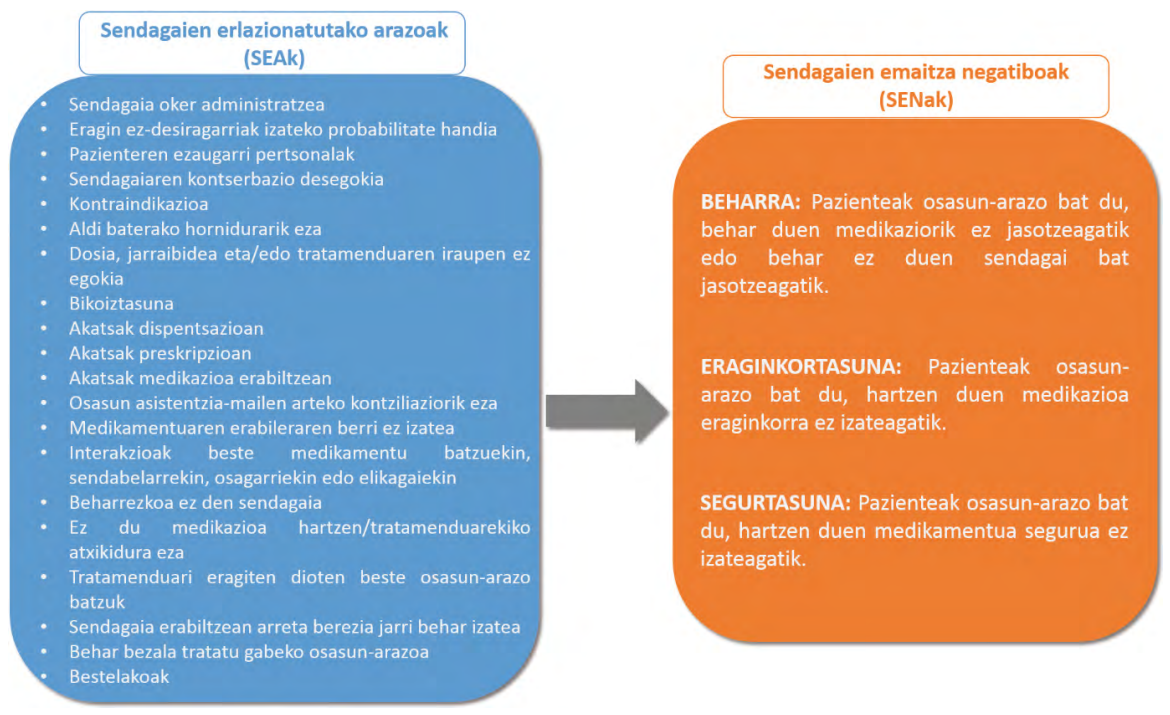

2. irudia. Foroak eta AF-FC Foroak proposatutako SEAk eta SENak.

\subsubsection{Medikamentuen erabilerara zuzendutako zerbitzuak}

\subsubsection{Dispentsazioa}

Dispentsazioa, farmazialariaren jarduera profesionalaren funtsezko zerbitzua da, herritarrek medikamentuak eskura edukitzeko, pazienteek medikamentuak behar bezala erabiltzen direla jakiteko behar adinako informazioa emateko, eta medikamentuekin lotutako zenbait arazo saihestu eta zuzentzeko aukera ematen duena. Osasun-produktuei ere aplika dakieke [13].

Farmazialari batek, sendagai bat dispentsatzen duenean (preskribatutakoa edo errezeta gabekoa), egiaztatu behar du pazienteak edo haren zaintzaileak erabilera eraginkor eta segurua bermatzeko behar besteko informazioa duela produktuari buruz. Halaber, e-errezetaren bitartez eskura duen informazioa erabiliz, eta elkarrizketan jasotzen dituen datuak bitarteko, ebaluatzen du medikamentua pazientearentzat egokia den, araudia betetzen duen, eta, azkenik, entregatzen duen ala ez erabakitzen du [13, 17]. Horretarako, protokolizatutako galdetegi bat erabiltzen du. 
Xabier Aizpurua-Arruti, Arantxa Isla, María Ángeles Solinís, Begoña Calvo, Ana del Pozo-Rodríguez, Estibaliz Goyenechea

Farmazialariaren parte-hartze aktiboaren ondorioz, gizarteak hautematen du sendagaia osasun-ondasun bat dela, eta ez kontsumo-objektu soil bat; gainera, pazientearen eta farmaziaren arteko harremana sendotzen laguntzen du.

\subsubsection{Indikazioa}

Osasun-arazo konkretu baterako hartu beharreko medikamentua zein den jakin gabe farmaziara doan paziente edo erabiltzaileak farmazialariari sendagai egokienaren eskaera egindakoan eskainitako FZPA da indikazioa. «Zer emango zenidake...?» esaldiarekin sinbolizatzen da [13].

Farmazialariak, osasun-agente gisa, sintoma «arinak» hobetzeko edo arintzeko funtsezko eginkizuna du. Sintoma arina osasun-arazo ez-larria da, automugatua eta iraupen laburrekoa; ez du diagnostiko medikorik behar; ez dago pazientearen beste osasun-arazo edo tratamendu batzuekin lotuta, eta medikuaren preskripziorik behar ez duen tratamendu batekin arintzen da. Eginkizun hori egiteko, prozesu metodologiko estandarizatu bat garatzen da, eta bideratzeko adostutako irizpideak zein azken ebidentziaren arabera egindako gida farmakoterapeutikoak erabiltzen dira [13, 17].

\subsubsection{Medikazioaren kontziliazioa}

Medikazio-akats asko, asistentzia-mailen arteko koordinazio-arazoengatik sortzen dira. Izan ere, asistentzia-trantsizioak gertatzen direnean tratamendu farmakologikoekin arazorik ez egotea da kontziliazioaren helburu kritikoa; hots, pazientearen segurtasuna mantentzea, batez ere ospitaleko alta ematerakoan.

Kontziliazioa egitean, farmazialariak era sistematikoan eta protokolo baten arabera alderatzen ditu pazienteak asistentzia-mailetatik igaro aurretik eta ondoren hartu dituen medikamentuen zerrendak. Farmazialariak desberdintasunak identifikatu behar ditu, ondoren aztertu, ebaluatu eta erabakiak hartu ahal izateko. Eraginkortasuna eta segurtasuna bermatzeko helburuarekin, beharrezko esku-hartzeak egingo ditu, prozesuan parte hartzen duten osasun profesionalekin elkarlanean $[13,17]$.

\subsubsection{Atxikidura terapeutikoa}

Paziente batek tratamendu batekiko atxikidura duela esaten da medikazioa agindu zaion bezala hartzen duenean [18]. Zenbait lanen arabera, $[19,20]$ gaixotasun kronikoak dituzten pazienteen $\% 50$ inguru ez zaie beren sendagaiei atxikitzen. Atxikidura terapeutiko eza arazo ekonomiko eta sanitario handia da gaur egun osasun-sistementzat, eta, ondorioz, pazienteari agindutako tratamenduak betetzen laguntzen dion berariazko 
zerbitzu bat beharrezkoa da, pazientearen osasunean eragin onuragarria izango duena [21].

Atxikidura terapeutikoa hobetzeko zerbitzuan, farmazialariak, bere esku-hartzearen bidez, aktiboki laguntzen dio pazienteari, bere borondatez jarrai diezaien osasun-profesionalak emandako gomendioei, medikamentuak eta osasun-produktuak erabiltzeko modu, ohitura higieniko-dietetiko eta/ edo bizimoduari buruzkoei, pazientearen osasunean espero diren emaitzak lortzeko $[13,17]$.

\subsubsection{Botika kutxen berrikuspena}

Zerbitzu honen helburu nagusia pazienteek beren etxeetan edo egoitzetan dituzten botiken aldizkako berrikuspenean datza. Adineko paziente polimedikatuek dute medikazioaren ondorio negatiboak jasateko arrisku handiena; beraz, horiei eskaintzen zaie zerbitzua, eta bai medikazioa kudeatzen laguntzeko beharra duten pazienteei ere.

Pazientearen botikina berrikusiko da, iraungitako edo kontserbazio-baldintza txarretan dauden sendagaiak erretiratzeko eta sendagaiak baldintza desegokietan erabiltzea saihesteko.

\subsubsection{Formulazio magistrala}

Formulazio magistrala pertsona konkretu batentzat prestatzen den sendagaia da, farmazialari batek edo haren zuzendaritzapean prestatua, eta zuzen presta dadin printzipio aktiboen preskripzio xehatua duena; horretarako, ezarritako elaborazio egokiko eta kalitate-kontroleko arauen arabera egiten da, farmazia komunitarioan edo ospitaleko farmazia zerbitzue$\tan [15]$.

Formulazio magistrala farmazia-lanbidearen jatorriaren lekuko adierazgarrienetako bat da, eta farmazialariaren jardueraren funtsarekin gehien errotutako jardueretako bat. Sendagaien fabrikazio industrialak gora egin duen arren, formulazio magistrala egitea ezinbestekoa da kasu espezifikoen tratamenduan. Kasu ohikoen artean, pediatrian erabiltzeko formulazio magistralak ditugu: askotan, dosi pediatrikoak ez daude eskuragarri; hau da, industrialki fabrikatutako sendagaiak ez dira merkaturatzen haurrek behar dituzten dosiekin, eta, ondorioz, formulazio magistralak ezinbestekoak dira ume horiek behar duten tratamendua jaso dezaten.

\subsubsection{Medikazioaren erabileraren berrikuspena}

Zerbitzu horretan, farmazialariak, pazientearekin (edo zaintzailearekin) batera, honek bere sendagaiei buruz duen ezagutza-mailaren eta sendagai 
Xabier Aizpurua-Arruti, Arantxa Isla, María Ángeles Solinís, Begoña Calvo, Ana del Pozo-Rodríguez, Estibaliz Goyenechea

horiei egiten dien erabileraren berrikuspen egituratua egiten du. Sendagaien erabilera zuzenari buruzko aholkularitza eskaintzen zaio, eta pazienteak sendagaiak zergatik hartu behar dituen ikusi eta horiek nola erabili eta/ edo administratu behar dituen ulertzen duela ziurtatzen da. Arazorik identifikatuko balitz, beharrezko aldaketak egin, eta, hala balegokio, preskribatu duen medikuari inprimaki baten bidez jakinaraziko litzaioke [22]. Zerbitzu hori bereziki erabilgarria da sendagai konplexuekin, hala nola inhalagailuekin edo sistema autoinjektagarriekin, tratamenduan dauden pazienteen kasuan.

\subsubsection{Sendagaiei buruzko aholkularitza}

Farmazian zerbitzu hori eskaintzea ezinbestekoa da; aurreko zerbitzu askorekin loturiko zerbitzu bat da. Eguneroko informazioa eskaintzen da sendagaiak era egokian erabiltzeko, ahalik eta erreakzio ez-desiragarri gutxien sortzeko eta medikazioaren atxikidura egokia izateko. Paziente baten sendagaien inguruko edozein kontsultari, informazio fidagarriaren eta azkeneko ebidentzia zientifikoaren arabera erantzungo zaio.

\subsubsection{Osasunean medikamentuen emaitzak ebaluatzera eta hobetzera zuzendutako zerbitzuak}

\subsubsection{Jarraipen farmakoterapeutikoa (JFT)}

SEAk detektatzea helburu nagusitzat duen zerbitzu profesionala da; haren bidez, SENak saihesten eta ebazten dira. Farmazialariak elkarrizketa pertsonalen sekuentzia bat ezarriko du; horrela, harreman profesional bat sortuko du, pazienteak aipatutako farmakoterapian eta osasun-arazoetan zentratua, emaitza optimoak lortuko, eta, bestela, detektatutako edo agertzeko arriskuan dauden SEAk edo SENak zuzentzeko esku hartuko. Zerbitzu horrek konpromisoa eskatzen du, eta modu jarraitu, sistematizatu eta dokumentatuan eman behar da. Farmazialariak, konpromiso horren bitartez, farmakoterapia osasunerako onuragarria izan dadin bere esku dagoen guztia egiteko erantzukizuna hartzen du [13].

\subsubsection{Farmakozaintza}

Kontrako erreakzio berriei buruzko informazioa identifikatu eta pazienteen kalteak prebenitzekotan, sendagaien, produktu biologikoen, sendabelarren eta botika tradizionalen ondorioei buruzko informazioa bildu, zaindu, ikertu eta ebaluatu nahi duen zientzia da [16].

Sendagai jakin batean hautemandako kontrako erreakzioen susmoak sistema zentralizatu baten bidez jakinarazi behar dira. Sistema horrek aukera ematen du kontrako erreakzio horiek estatuan eta nazioartean ezagutarazteko. 


\subsection{Komunitateko osasunarekin erlazionaturiko zerbitzuak}

Komunitateko osasunarekin erlazionaturiko zerbitzuak farmazialari batek bere gaitasun profesionalak erabiliz egiten dituen jarduerak dira, osasunaren hezkuntzan, sustapenean eta babesean eta gaixotasunaren prebentzioan zentratzen direnak. Horretarako, kasu bakoitzean, osasun publikoko programak eta/edo baliabide egokiak erabiltzen dira, inplikatutako eragile guztiekin lankidetzan [16]. Zerbitzu horien helburu nagusiak hauek dira:

- Osasuna eta bizi-ohitura osasungarriak sustatzea.

- Hainbat motatako gaixotasunei aurrea hartzea, bereziki gaixotasun kronikoei.

- Konplikazioak ez agertzea.

- Diagnostikatu gabeko zenbait patologiaren diagnostiko goiztiarra erraztea.

- Osasun-agintariek eta beste kolektibo batzuek sustatutako osasun publikoko jarduerak herritarrek eskura ditzaten laguntzea.

\section{FZPAk EUSKAL AUTONOMIA ERKIDEGOAN (EAE)}

Duela urte batzuk, EAEko Farmazialarien Kontseiluarekin bat eginda, EAEko farmaziak FZPAk eskaintzen hasi ziren. Atal honetan, EAEko farmazietan azkenaldian eman diren eta oraindik ematen ari diren FZPAk azalduko dira. Zerbitzu horietaz gain, farmazia bakoitzak beste hainbat zerbitzu jartzen ditu herritarren eskura (2. Irudian, letra zurian daudenak): medikamentuei buruzko aholkularitza, indikazioa, neurri antropometrikoak, parametro klinikoen determinazioa, osasunaren sustapena, nutrizio-aholkularitza, besteak beste.

\subsection{Dispentsazioa}

2020an EAEko hainbat farmazia CGCOFak bideratutako Hazfarma izeneko proiektuan parte hartzen hasi dira [15]: sendagaien dispentsazioak «Nodofarma Asistencial» izeneko plataforman modu egoki eta protokolarizatuan erregistratzen dira. Erregistroak gordeta geratzen dira, eta zerbitzu horren jarraipen espezifikoa egin daiteke. Gipuzkoako farmaziek, bestalde, estatu-mailan egindako D-VALOR programan ere parte hartu zuten, bentzodiazepinen dispentzazioaren ebaluazioa egiteko [23].

\subsection{Medikazioaren kontziliazioa}

EAEko farmazialariek kontziliazio-programa batean parte hartu zuten 2015-2016 urte bitartean. Programa hori Gipuzkoako Sendagaigileen Elkartearen (GSE) eta Bidasoako Erakunde Sanitario Integralaren (ESI) 
Xabier Aizpurua-Arruti, Arantxa Isla, María Ángeles Solinís, Begoña Calvo, Ana del Pozo-Rodríguez, Estibaliz Goyenechea

artean garatu zen. Bertan, pazienteak bere tratamendu aktiboaren orrian preskribatutako sendagaien eta benetan hartzen zuenaren arteko desberdintasunak identifikatzen ziren [24].

Programaren helburua zen desadostasunek eragindako medikazio-akatsak saihestea, eremu horretako lehen mailako arretako farmazia komunitarioen, medikuen eta lehen mailako arretako farmazialarien lankidetzaren bidez. Programa horri esker, sendagai batez murriztu zen, batez beste, agindutako sendagaien kopurua, parte hartu zuen paziente bakoitzeko. Gainera, ospitaleratzeak ere murriztu ziren estatistikoki, eta zerbitzua kostu eraginkorra zela frogatu zen [24].

\subsection{Atxikidura terapeutikoa}

EAEn, 2 proiektu nagusi landu dira gai honen inguruan aurrera pauso bat emateko: Adtra-lip (GSE eta OAT taldearen artean bideratua) eta AdherenciaMED (CGCOF-ak gidatua).

Adtra-lipen proiektuaren helburu nagusia zen hiperkolesterolemia duten pazienteen tratamenduarekiko atxikidura hobetzea estatu mailan. Gaixotasun metaboliko kronikoa izanik, tratamendu farmakologikoa ere bizitza osorakoa da; hori dela eta, gaixoek tratamendu farmakologikoarekiko atxikidura-falta handiagoa izaten dute. Proiektu hori, EAEn, 2014-2016 bitartean eraman zen aurrera [25]. Programan parte hartu zuten pazienteen artean, eta esku-hartze farmazeutikoaren ondoren, ikusi zen hiperkolesterolemia zuten pazienteek \% 73ko atxikidura izan zutela. Sei hilabetean atxikitzaile bihurtzeko aukerak handiagoak izan ziren farmazialariaren esku-hartzea izan zuen paziente-taldean, inolako esku-hartzerik izan ez zuen paziente-taldean baino.

AdherenciaMED proiektuaren helburua, bestalde, hipertentsio arteriala, asma edo biriketako gaixotasun buxatzaile kronikoa (BGBK) zuten pazienteen tratamendu farmakologikoarekiko atxikidura terapeutikoa hobetzera bideratutako zerbitzu baten eragin klinikoa, ekonomikoa eta humanistikoa diseinatzea eta ebaluatzea zen, ohiko arretarekin alderatuta. Proiektua 2017. urtean egin zen, eta administrazio publikoak finantzatu zuen proiektua [26]. Programaren hasieran, pazienteen $\% 35,1 \mathrm{ek}$ ez zuen atxikidura tratamenduarekin; hilabeteko jarraipenaren ondoren, atxikidura zuten pazienteen kopuruak \% 22,8 egin zuen gora. Horrek programak emaitza klinikoetan eta humanistikoetan duen eragina erakutsi zuen.

\subsection{Botika kutxen berrikuspena}

Botika-kutxen berrikuspena bereziki adineko pertsona polimedikatuei zuzenduta dagoenez, Hurkoa erakundeak (irabazi-asmorik gabeko erakundea; hauskortasun-egoeran dauden adinekoen edo gaixotasun mentala du- 
ten pertsonen eskubideak zaindu eta defendatzen ditu) eta EAEko farmaziek kolaborazio bat egin zuten ospitaleratuta ez dauden pazienteen behar farmakoterapeutikoen erantzule farmazialari komunitarioa izan zedin. Prozesu horretan, Hurkoako teknikariak hauskortasun-egoeran zegoen paziente bakoitzaren beharrak balioztatu zituen. Behin medikazioarekin arazoak zituen pazientea detektatuta, haren erreferentzia-farmazia aukeratu, eta bisita antolatzen zen, farmazian edo etxean; bisitan, botika-kutxen berrikuspena egiten zen, beste zerbitzu askorekin batera [27].

\subsection{Formulazio magistrala}

Kasu berezietan aukera terapeutiko indibidualizatuak izateko, ezinbestekoa da formulazio magistrala. Zerbitzu horrek kostu bat du: formula bakoitzak prezioa du, zehaztutako prezio-zerrenda baten arabera; haren ordainketa administrazioaren eta pazientearen artean banatzen da. 2019. urtetik errezeta elektronikoaren barnean daude EAEn preskriba daitezkeen formula magistral batzuk.

\subsection{Medikazioaren berrikuspena}

EAEn, eta Eusko Jaurlaritzako Farmazia Zuzendaritzarekin hitzartuta, «Medikazioaren erabilera hobetzea etxez etxeko laguntza-zerbitzuei atxikitako pazienteei» izeneko proiektu bat dago martxan 2009. urtetik. Udaletxeak atxiki dakizkioke programa horri, eta behin gizarte teknikariak pazientea detektaturik eta haren beharrak ikusirik, farmaziak dosifikazio-sistema pertsonalizatuak (DSPak) presta ditzake pazientearentzat. DSPak lehen mailako baliabidea dira farmazia komunitarioaren bidez tratamenduekiko atxikidura eta segurtasuna hobetzeko. Modu horretara, medikazioarekin lotutako arazoak prebenitu eta konpon daitezke. DSPen prestaketan, farmazialariak lan sakona egin behar du medikazioaren berrikuspenean, oso garbi eduki behar baitira zeintzuk diren pazienteak aktibo dituen tratamenduak (zer medikamentu, noiz eta nola hartu behar duen) eta horretarako jarraipen zorrotza behar da. Proiektu horretan, pazienteak ez du ezer ordaindu behar eta administrazioak hilabetero farmaziari ordaintzen dio paziente konkretu bakoitzarengatik dagokion ordainsaria [28]. Programa horrekin sistema publikoa aurreztea lortzen da, beharrezkoak ez diren errezetak murriztuz. Artatutako pertsonentzako zerbitzua hobetzeaz gain, baliabide soziosanitarioen aprobetxamendua eta sinergia ere handiagoa da.

\subsection{Jarraipen farmakoterapeutikoa}

EAEn, orain arte, JFTeko zerbitzuan oinarritutako bi proiektu jarri dira martxan: conSIGUE eta SFT DMII (Jarraipen farmakoterapeutikoa Diabetes Mellitus II-a duten pazienteetan). 
Xabier Aizpurua-Arruti, Arantxa Isla, María Ángeles Solinís, Begoña Calvo, Ana del Pozo-Rodríguez, Estibaliz Goyenechea

ConSIGUE programak (CGCOFak gidatua), JFaren eragin klinikoa, ekonomikoa eta humanistikoa neurtu zituen estatu-mailako farmazietako adineko heldu polimedikatuetan. Programa horretan, EAEko 78 farmaziak hartu zuten parte. Zerbitzuak pazienteen osasunean izan duen eragina erakutsi du [29], kostu-efektiboa da [30] eta JFT zerbitzuan inbertitutako euro bakoitzeko 3,3€-tik 6,2€-ra bitarteko etekina sortzen da [31]. Bestalde, kontrolatu gabeko osasun-arazoak \% 54,1, larrialdietara bisitak \% 53,1 eta ospitaleratzeak \% 59,8 murriztu zituen.

Bestalde, EAEko paziente kroniko eta polimedikatuen JFTeko programan (SFT DMII eta Eusko Jaurlaritzako Farmazia Zuzendaritzarekin hitzartuta), II motako diabetesa zuten eta aldi berean 8 printzipio aktibo edo gehiago hartzen zituzten pazienteak izan ziren zerbitzuaren onuradunak. Bertan, farmaziek administrazioaren aldetik ordainsaria izan zuten. 2018an abian jarritako programa horretan; EAEko lehen mailako arretako medikuak, erizainak eta farmazeutikoak eta farmazia komunitarioko langileak ziren parte-hartzaileak. Programa horretan, pazienteek hartzen zituzten sendagaiak eta preskribatutako sendagaiak farmazia komunitarioetan berrikusten ziren, Euskal Osasun Zerbitzuko lehen mailako arretako zentroekin koordinatuta. Farmazialariek SEA edo SENen susmoren bat hautematen bazuten, osasun-zentroko medikuekin harremanetan jarriko ziren. JFT egoki bat egiteko, pazienteek beren farmazia komunitariora joan behar zuten urtebetez aldizkako elkarrizketa batzuetara, farmazietatik lehen mailako arretako medikuei egindako proposamenen emaitzak ebaluatzeko. Programa horren emaitzak eta ondorioak ez dira izan oraindik argitaratuak.

\subsection{Gaixotasunaren prebentzioa}

Osasunaren arloko prebentzioa osasuntsu egoten laguntzen duten ohiturak edo jokabideak aldatzean datza. Helburua, herritarrak gaixotasun kronikoekiko eta horien prebentzioarekiko sentsibilizatzea da.

1989az geroztik, Giza Immunoeskasiaren Birusa (GIB) prebenitzeko eta diagnostikatzeko 6 programa [32] ezarri dira EAEko farmazia komunitarioetan (2. taula). Horiek Eusko Jaurlaritzako Farmazia Zuzendaritzarekin hitzartuta daude eta, kasu gehienetan administrazioak eta pazienteek elkarren artean ordaintzen dituzten arren, zenbat kasutan, dohainak izaten dira pazientearentzat: adibidez, metadona bidezko mantentze-programa.

Bestalde, giltzurrunetako gaixotasunaren arriskuaren detekzio-programa ere eskaintzen da, giltzurrunaren mundu egunean. Bertan, farmaziek glukosaren, kreatininaren eta arteria-presioaren zehaztapenak egiten dituzte, bai eta giltzurrun-gaixotasun posiblearen baheketa-parametroak ere, doan, eskatzen duten erabiltzaileei. 
2. taula. GIBa prebenitzeko eta diagnostikatzeko programak.

1. Hiesaren aurkako kitak ematea (xiringa, preserbatiboa, eskuoihal higienikoa, ur esterila eta nahasteko ontzia), injekziorako material esterilera errazago iristeko

2. Xiringak Trukatzeko Programa (BJP), bide publikoetan utzitako xiringa kopurua murrizteko eta osasun-hezkuntza egiteko helburuarekin

3. $3 \times 1$ preserbatiboren salmenta diruz lagundua ( 3 unitate euro 1eko), preserbatiboaren irisgarritasuna hobetzeko helburuarekin

4. Metadona bidezko mantentze-programa, drogen erabiltzaileen arriskuak murrizteko eta bizi-kalitatea hobetzeko bide parenteraletik

5. GIBaren test azkarra, GIBaren detekzio goiztiarra errazteko, test aurreko eta osteko aholkuarekin eta deribazioarekin batera

6. Sifilisaren test azkarra, gizonekin sexua duten gizonentzat, GIBaren baheketa osagarri gisa eskainia

2018. urtean, Gipuzkoako farmazia komunitarioetan, II motako diabetesaren arriskua detektatzeko programa ere egin zen 6 hilabetean. Programa horretan, 72 farmaziak diabetesa izateko arriskuan zeuden 45 urtetik gorako pertsonak garaiz detektatzen eta arrisku hori murrizten jardun zuten, pertsona horiek ohitura higieniko-dietetiko egokietan heziz. Horretarako, baheketa egin zuten, test bat betez (Findrisc testa), II motako diabetesa garatzeko arrisku handia zuten pertsonak detektatzeko. 1.881 paziente errekrutatu zituzten. Horietatik, \% 15,7k arrisku txikia zuen hurrengo 10 urteetan DM2a izateko; \% 64,9k arrisku moderatua, eta \% 19,5ek arrisku altua. Farmazialariaren interbentzioari dagokionez, 1.351 pazientek osasun-heziketa jaso zuten, eta 340ri glukosaren neurketa egin zitzaien. Glukosaneurketen erantzunak bi taldetan banatu ziren: $<110 \mathrm{mg} / \mathrm{dl}(\mathrm{n}=224)$ eta $\geq 110 \mathrm{mg} / \mathrm{dl}(\mathrm{n}=116) .110 \mathrm{mg} / \mathrm{dl}$-tik gorako glukosa-balioak zituzten pazienteak medikuarengana bideratu ziren. Hamabost pazienteri (guztizkoaren $\% 1,4)$ neurri higieniko-dietetikoen tratamendua edo tratamendu farmakologikoa ezarri zieten [33].

\subsection{Tabakoarekiko mendekotasuna}

Biztanleriari tabako-ohiturak uzten laguntzeko, EAEko farmazietan tabakoaren mendekotasuna gainditzeko programa 2016. urtean ezarri zen.

Tabako-mendekotasuna gainditzeko tratamendua oso eraginkorra da, eta giza sufrimendu handia eta osasun-kostu handia dakarten gaixotasun 
Xabier Aizpurua-Arruti, Arantxa Isla, María Ángeles Solinís, Begoña Calvo, Ana del Pozo-Rodríguez, Estibaliz Goyenechea

kroniko asko ekidin ditzake (minbizia, BGBK, gaixotasun kardiobaskularrak...).

Programan parte hartzen duten farmazialariek tabakoak osasunean dituen kalteei eta tabako-ohitura uzteko dauden aukera terapeutikoei buruzko informazioa zabaltzen dute. Programan parte hartu nahi duten pertsonek farmazialariaren laguntza dute; farmazialaria, halaber, farmakoterapiaren eraginkortasun eta segurtasun handiena lortzekotan medikazio erabiliaren jarraipena egiteaz ere arduratzen da.

\subsection{Ikergai diren bestelako zerbitzuak}

EAEn, sendagaien segurtasuna eta erabilera ebaluatzeko eta hobetzeko (SSUM) programa dago UPV/EHUrekin lankidetzan. Programa hori II motako diabetesa, BGBK edo gaixotasun kardiobaskularra duten eta jarraipen gehigarriko medikamentuekin tratamenduan dauden pazienteei zuzenduta dago. 2019an jarri zen martxan, Gipuzkoako Debagoieneko Erakunde Sanitario Integraleko (ESI) 13 farmazia komunitarioen parte-hartzearekin. Farmazia bakoitzak aldizkako elkarrizketak egiten dizkio parte hartzen duen paziente bakoitzari tratamenduarekiko atxikipena, sendagaiarekiko ezagutza eta erabilera eta segurtasuna balioztatzeko eta hobetzeko. Programa oraindik abian dago, eta egun 81 paziente ari dira parte hartzen. 141 intzidentzia detektatu dira; horietatik \% 9,9 atxikipenarekin lotuta zeuden; \% 53,9 ezagutzarekin eta erabilerarekin, eta \% 36,2 segurtasunarekin. Hirugarren elkarrizketan, ikusi da intzidentzia-kopurua \% 66 murriztu dela lehenengoarekin alderatuta, eta murrizketa hori \% 75ekoa izan da atxikimenduan; \% 61,1ekoa ezagutzan eta erabileran, eta \% 61,9koa segurtasunean.

\section{FZPAen ONURAK ETA ERRONKAK}

Farmazialariek zerbitzuen garapenarekin lotutako jardueretan modu homogeneoan eta sistematizatuan parte hartzen dute, eta jarduera horien erregistroa egiten dute. Horrek zerbitzuen jarraipena eta ebaluazioa egitea ahalbidetzen du, eta aurrerapausoak ematea ere. Baina FZPAk eskaintzeak eta kudeatzeak kostu handia eragiten die farmaziei, denbora eta esfortzu handiak behar baitira jarduerak modu egokian egiteko. Ondorioz, zerbitzu horien eskaintza zabaltzeko, ezinbestekoa da farmazialarien motibazioa sustatzea, eta haren jarrera aldatzea eragin dezaketen arrazoiak identifikatzea.

Ildo horretan, frogatu da FZPAk ezarriz onurak lortzen direla gizartean, farmazialarien kolektiboan, farmazialarietan eta pazientetan (3. irudia) [13]: 
- Jasotako zerbitzua hobetzea

-Zaintza-maila handiagoa

- Laguntza homogeneo eta estandarizatua

-Asistentziaren kalitatea
- Gogobetetze profesionala

-Inplikazio aktiboagoa osasun-prozesue

-Erantzukizun berriak eta garrantzitsuak

-Diziplina anitzeko osasun-taldeetan pa
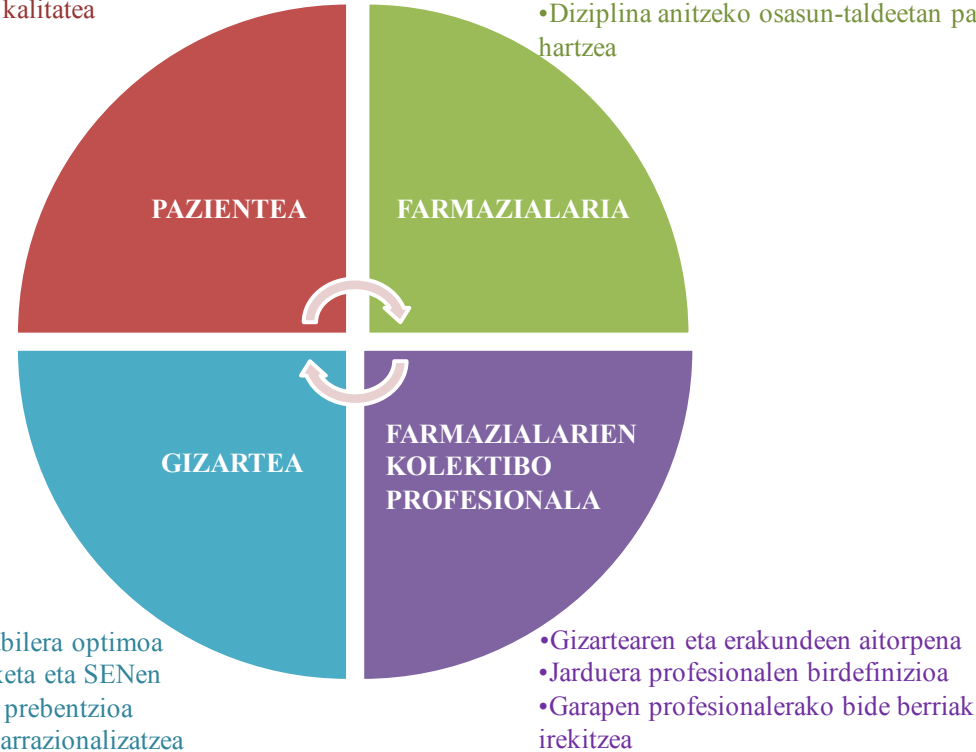

konponketa edo prebentzioa

- Osasun-gastua arrazionalizatzea

-Ekitatea laguntza-zerbitzuetan

3. irudia. FZPAen onurak.

Bestalde, farmazia komunitarioan FZPAk erabat ezartzeko eta orokortzeko, ordainsaria da egungo erronka: adierazi bezala, hainbat zerbitzuk ordainsari bat jasotzen dute, eta hori kontuan izan beharreko gaia da zerbitzu berriak martxan jartzeko garaian; izan ere, jarduera batek errentagarritasunik sortzen ez badu, oso litekeena da etorkizun hurbilean hornitzeari uztea [34]. Ordainketa modu ezberdinetan egin daiteke, zerbitzuaren eta pertsona edo erakunde finantzatzailearen arabera: (i) pazienteak zerbitzua osorik ordaintzen du, (ii) pazienteak zerbitzuaren zati bat ordaintzen du eta administrazioak gainerakoa, edo (iii) administrazioak zerbitzua osorik ordaintzen du.

Beste herrialde batzuetan, zerbitzuen ordainsaria gero eta nabarmenagoa da: Ingalaterran, Australian edo Zeelanda Berrian, esaterako. Herrialde horietan, farmazia asistentziala eta arreta farmazeutikoa garatuago daude.

Ingalaterran, farmazia komunitarioaren finantzaketak zerbitzu aurreratuengatiko ordainsari bat (aukerakoak dira), oinarrizko zerbitzuetarako estaldura-tasa bat (farmazia guztiek eskaini behar dituzte) eta beste marjina batzuk ditu [35, 36]. Dispentsazio-zerbitzua funtsezko zerbitzutzat hartzen 
da, eta kantitate ekonomiko finko bat ordaintzen da dispentsazio bakoitzeko [37]. Zerbitzu aurreratuetan, zerbitzuaren araberakoa da ordainsaria: sendagaien erabilera berrikustea (RUM), gailuen erabilera berrikustea (AUR), estomen pertsonalizazioa (SAC), gripearen aurkako txertoaren zerbitzua eta farmazialari komunitarioaren kontsulta-zerbitzua (CPCS) [38]. Ordainketa guztiak Erresuma Batuko Osasun Sistema Nazionalak (NHS) ordaintzen ditu.

Australian, Community Pharmacy Programs izeneko programan partaide diren farmaziek Gobernu Federalaren ordainsaria jasotzen dute, sendagaien atxikidura- eta erabilera-programetan, Torresko Itsasarteko uharteetako pertsonentzako programa espezifikoetan, landa-laguntzako programetan eta osasun-programetan. Kasu batzuetan, medikazioa berrikusteko eta immunizatzeko beste zerbitzu batzuk ere ordaintzen dira [36].

Zeelanda Berrian, dispentsazio bakoitzeko, barruti bakoitzeko Osasun Sailak ordaintzen dio farmaziari. Dispentsazioaz gain, finantzatutako beste zerbitzu batzuk ere badaude, hala nola paziente kronikoentzako zerbitzua, antikoagulatzaileekin tratamenduak dituzten pazienteentzako jarraipen-zerbitzua, sendagaien erabilera berrikustea (RUM), medikamentuen ebaluazioa, klozapina emateko zerbitzua, egoitzetako arreta zerbitzuak eta opioideak batera dispentsatzeko zerbitzuak [35].

Dena den, ordainsaria lortzeko, zerbitzuak pazientearen bizi-kalitatea hobetzen dela demostratu behar du, hots, zerbitzua jasotzen duen pazientearengan hobekuntzak eragiten direla, eta administrazioarentzat etekin ekonomikoak sortzen direla. Hau da, errentagarria izan behar du.

\section{ONDORIOAK}

Farmazialariek ezagutza eta trebetasun espezifikoak dituzte, ongizatea lortzeaz gero eta kezkatuago dagoen eta osasunaren kontzeptuarekin lotutako alderdi guztietan informatua eta prestatua dagoen gizartearen bizi-kalitatea hobetzeko.

Ikusi den bezala, farmazialari-profesioa ez da duela urte batzuk bezalakoa. Oinarri nagusia sendagaia den arren, farmazialariek frogatu dute eskainitako zerbitzuek eta egindako esku-hartze klinikoek medikamentuen aurkako gertaerak murrizten eta pazientearen emaitza klinikoak eta humanistikoak hobetzen dituztela; beraz, farmazia komunitarioaren praktika gero eta asistentzialagoa bihurtzen ari da. FZPAek, aldaketa horretarako tresna garrantzitsua izanik, pazienteetan ez ezik, farmazialarien kolektiboan eta farmazialarietan euretan ere onurak sor ditzakete. Gainera, farmazia asistentzialak aurrera egiteak onura handiak ekarriko dizkio gizarteari, eta errentagarritasuna administrazio publikoei. 
Hala ere, farmazia asistentziala sustatzeko erronka garrantzitsuetako bat da pazienteek eta gainerako osasun-profesionalek horrelako esku-hartze klinikoen onurak ezagutzea, horrela farmazia komunitarioa osasun-sistema publikoetan sakonkiago integra dadin.

\section{ESKER ONAK}

Egileek UPV/EHUri eskertzen diote lan hau egiteko jasotako dirulaguntza (US18/24).

\section{BIBLIOGRAFIA}

[1] URICK BY, MEGGS EV. 2019. «Towards a Greater Professional Standing: Evolution of Pharmacy Practice and Education, 1920-2020». Pharmacy. 7(3):98.

[2] DALTON K, BYRNE S. 2017. «Role of the pharmacist in reducing healthcare costs: current insights». Integrated pharmacy research and practice. 6:37-46.

[3] MOLES RJ, STEHLIK P. 2015. «Pharmacy Practice in Australia». The Canadian Journal of Hospital Pharmacy. 7:68(5).

[4] HEPLER CD, STRAND LM. 1990. «Opportunities and responsibilites in Pharmaceutical Care». Am. J. Pharm 1990; 47:533-543.

[5] UNIVERSIDAD DE GRANADA. GRUPO DE INVESTIGACIÓN EN ATENCIÓN FARMACÉUTICA. 2006. «Seguimiento farmacoterapéutico: Método Dáder (3. revisión: 2005)». Pharmacy Pract (Granada).4, n.1, pp. 44-53.

[6] ORGANIZACIÓN MUNDIAL DE LA SALUD (OMS). El papel del farmacéutico en el sistema de atención de salud. Informe de la Reunión de la OMS Tokio, Japón, 31 de agosto al 3 de septiembre de 1993. 2020ko ekainaren 19an sartua. Hemen eskuragarri: https://cutt.ly/dyIHScC

[7] MARTÍN-CALERO MJ, DE LA MATTA, M J, BERENGUER B, LA CASA C. 2004. «Pharmaceutical Care: Past, Present and Future». Current Pharmaceutical Design. 10(31):3931-46.

[8] 1/1994 LEGEA, EKAINAREN 17KOA, EUSKAL AUTONOMI ELKARTEKO ORDENAZIO FARMAZEUTIKORAKO DENA. 2020ko ekainaren 23an sartua. Hemen eskuragarri: https://www.legegunea.euskadi.eus/x59contfich/eu/contenidos/ley/bopv199402549/eu_def/index.shtml.

[9] MINISTERIO DE SANIDAD, CONSUMO Y BIENESTAR SOCIAL. CONSENSO SOBRE ATENCIÓN FARMACÉUTICA. 2020ko ekainaren 19an sartua. Hemen eskuragarri: https://www.mscbs.gob.es/profesionales/ farmacia/consenso/consenso.htm\#biblio

[10] CONSEJO GENERAL DE COLEGIOS OFICIALES DE FARMACÉUTICOS. 2018. FORO DE ATENCIÓN FARMACÉUTICA. PORTALFARMA. 2020ko ekainaren 19an sartua. Hemen eskuragarri: https://www.portalfarma. $\mathrm{com} /$ inicio/serviciosprofesionales/foroatencionfarma/Paginas/default.aspx 
Xabier Aizpurua-Arruti, Arantxa Isla, María Ángeles Solinís, Begoña Calvo, Ana del Pozo-Rodríguez, Estibaliz Goyenechea

[11] CONSEJO GENERAL DE COLEGIOS OFICIALES DE FARMACÉUTICOS. 2019. FORO DE ATENCIÓN FARMACÉUTICA EN FARMACIA COMUNITARIA. PORTALFARMA. 2020ko ekainaren 19an sartua. Hemen eskuragarri: https://www.portalfarma.com/inicio/serviciosprofesionales/ forofarmaciacomunitaria/Paginas/default.aspx.

[12] FORO DE ATENCIÓN FARMACÉUTICA-FARMACIA COMUNITARIA. COMUNICACIONES Y ARTÍCULOS DE INTERÉS. 2018. Portalfarma. 2020ko ekainaren 19an sartua. Hemen eskuragarri: https://www. portalfarma.com/Inicio/serviciosprofesionales/forofarmaciacomunitaria/ comunicaciones/Paginas/comunicacionesarticulosinteres.aspx

[13] FORO DE ATENCIÓN FARMACÉUTICA-FARMACIA COMUNITARIA (FORO AF-FC). GUÍA PRÁCTICA PARA LOS SERVICIOS PROFESIONALES FARMACÉUTICOS ASISTENCIALES EN LA FARMACIA COMUNITARIA. MADRID: CONSEJO GENERAL DE COLEGIOS OFICIALES DE FARMACÉUTICOS; 2019. 2020ko ekainaren 19an sartua. Hemen eskuragarri: https://www.portalfarma.com/Profesionales/consejoinforma/ Paginas/2020-guia-spfa-foro-af-fc-farmacia-comunitaria.aspx

[14] WIEDENMAYER K, et al. 2006. «Developing a Pharmacy practice. A focus on patient care». The Hague: Ed. WHO and FIP.

[15] CONSEJO GENERAL DE COLEGIOS OFICIALES DE FARMACÉUTICOS. 2020. Hazfarma. Portalfarma. 2020ko ekainaren 19an sartua. Hemen eskuragarri: https://www.portalfarma.com/inicio/serviciosprofesionales/ Hazfarma/Paginas/Hazfarma.aspx

[16] CONSEJO GENERAL DE COLEGIOS OFICIALES DE FARMACÉUTICOS. 2013. DOCUMENTO DE BUENAS PRÁCTICAS EN FARMACIA COMUNITARIA EN ESPAÑA. 2020ko ekainaren 19an sartua. Hemen eskuragarri: http://www.portalfarma.com/Profesionales/Buenas-practicasprofesionales/Paginas/Buenas-practicas-Farmacia-Comunitaria.aspx

[17] BENEDÍ, J. RODRÍGUEZ, M. (EDS). 2019. Atención Farmacéutica. Dextra Editorial S.L. ISBN: 978-84.17946-08-1.

[18] VRIJENS B, DE GEEST S, HUGHES DA, PRZEMYSLAW K, DEMONCEAU J, RUPPAR T, et al. 2012. «A new taxonomy for describing and defining adherence to medications». Br J Clin Pharmacol; 73:691-705.

[19] NÚNEEZ MONTENEGRO AJ, MONTIEL LUQUE A, MARTÍN AURIOLES E, TORRES VERDÚ B, LARA MORENO C, GONZÁLEZ CORREA JA. 2014. «Adherencia al tratamiento en pacientes polimedicados mayores de 65 años con prescripción por principio activo». Aten Primaria; 46:238-45.

[20] IBARRA BARRUETA O, MORILLO VERDUGO R, RUDI SOLA N, VENTURA CERDÁ JM, NAVARRO AZNÁREZ H. 2015. «Adherencia en pacientes en tratamiento crónico: resultados del Día de la Adherencia del 2013». Farm Hosp; 39:109-13.17.

[21] MARTÍNEZ-MARTÍNEZ F, GARCÍA MV, GASTELURRUTIA MA, VARAS R, PEIRÓ T, SÁEZ-BENITO L, et al. 2019. «Informe Global 2019 
AdherenciaMED: Diseño, evaluación del impacto e implantación de un Servicio profesional de Adherencia Terapéutica desde el ámbito de la Farmacia Comunitaria». 2020ko ekainaren 23an sartua. Hemen eskuragarri: https://www.portalfarma.com/Profesionales/InvestigacionFarmacia/ AdherenciaMED/Documents/2019-informe-resultados-adherenciamed.pdf

[22] BAIXAULI VJ. 2015. «Revisión del uso de los medicamentos (RUM), un nuevo servicio profesional en la farmacia comunitaria española». Farmacéuticos Comunitarios. 7 (4): 3-4.

[23] CÁMARA R, COSÍN A, DAGO A, GUTIÉRREZ P, SALAR L, SOLÁ N. 2013. «Programa D-VALOR, análisis de registros de dispensación. Benzodiazepinas». Pharm Care Esp. 15(4): 140-146.

[24] OÑATIBIA-ASTIBIA A, MALET-LARREA A, MENDIZABAL A, VALVERDE E, LARRAÑAGA B, GASTELURRUTIA MA, et al. 2020. «The medication discrepancy detection service: a cost-effective multidisciplinary clinical approach». Atención Primaria. Doi: 10.1016/j. aprim.2020.04.008.

[25] OÑATIBIA-ASTIBIA A, MALET-LARREA A, LARRAÑAGA B, GASTELURRUTIA MÁ, CALVO B, RAMÍREZ D, CANTERO I, GARAY Á, GOYENECHEA E. 2019. «Tailored interventions by community pharmacists and general practitioners improve adherence to statins in a Spanish randomized controlled trial». Health Serv Res. 54(3):658-668.

[26] GARCÍA-CÁRDENAS V, GASTELURRUTIA MA, MALET-LARREA A, PEIRÓ T, PÉREZ-ESCAMILLA B, SAEZ-BENITO L, TORRES-ROBLES AJ,VALVERDE MI, VARAS R, ZARZUELO MJ, BENRIMOJ SI, MARTÍNEZ-MARTÍNEZ F. 2019. «AdherenciaMED Project: Design, impactassessment and implementation of a professional service for therapeutic adherence at the community pharmacy setting». Consejo General de Colegios Oficiales de Farmacéuticos.

[27] AMAIA MALET, XABIER AIZPURUA, MIGUEL ÁNGEL GASTELURRUTIA, AINHOA OÑATIBIA, BELEN LARRAÑAGA, ESTIBALIZ GOYENECHEA. 2018. Programa piloto de atención farmacéutica domiciliaria a pacientes en situación de fragilidad en Gipuzkoa. XXI Congreso Nacional Farmacéutico.

[28] GASTELURRUTIA MA, LARRAÑAGA B, GARAY A. 2010. Resultados del programa para en usuarios de servicios sociales de Gipuzkoa. Optimizacion del uso de la medicación. XVII Congreso Nacional Farmacéutico.

[29] MARTÍNEZ-MARTÍNEZ F, GASTELURRUTIA MA, VARAS R, FAUS MJ, GARCÍA MV, JÓDAR F, et al. 2014. «Medida del Impacto del impacto clínico, económico y humanístico del servicio de seguimiento farmacoterapéutico en mayores polimedicados, en la farmacia comunitaria española». 2020ko ekainaren 23an sartua. Hemen eskuragarri: https:// www.portalfarma.com/Profesionales/InvestigacionFarmacia/conSIGUE/ Documents/Resultados-Definitivos-Programa-Consigue-Impacto-20112014.pdf 
[30] JÓDAR-SÁNCHEZ F, MALET-LARREA A, MARTÍN JJ, GARCÍA-MOCHÓN L, LÓPEZ DEL ALAMO MP, MARTÍNEZ-MARTÍNEZ F, et al. 2015. «Cost-Utility Analysis of a Medication Review with Follow-Up Service for Older Adults with Polypharmacy in Community Pharmacies in Spain: The conSIGUE Program». PharmacoEconomics; 33(6):599-610.

[31] MALET-LARREA A, GOYENECHEA E, GASTELURRUTIA MA, CALVO B, GARCÍA-CÁRDENAS V, CABASES JM, et al. 2017. «Cost analysis and cost-benefit analysis of a medication review with follow-up service in aged polypharmacy patients». Eur J Health Econ. 18(9):1069-1078.

[32] A ARRILLAGA ARRIZABALAGA, ML MARTÍNEZ GARCIA, A OÑATIBIA ASTIBIA, S SANZ OLMOS, I SANZ BERECIARTU, N LAJO ÁLVAREZ, A ARRAIZA ARMENDARIZ. 2019. Implicación de la farmacia comunitaria del País Vasco en la prevención y diagnóstico del VIH». XIX Congreso Nacional sobre el SIDA e ITS.

[33] OÑATIBIA-ASTIBIA A, MALET-LARREA A, LARRAÑAGA B, MARTIARENA A, GASTELURRUTIA MA, GARAY A, GOYENECHEA E. «Implantación del servicio de detección del riesgo de diabetes mellitus tipo2 en las farmacias comunitarias de Gipuzkoa». 2018. VIII Congreso Nacional de Farmacéuticos Comunitarios (SEFAC).

[34] GASTELURRUTIA MÁ. REMUNERACIÓN DE LOS SERVICIOS PROFESIONALES FARMACÉUTICOS. El Farmacéutico. 2017. 2020ko ekainaren 19an sartua. Hemen eskuragarri: http://elfarmaceutico.es/index. $\mathrm{php} / \mathrm{profesion} /$ item/7740-remuneracion-de-los-servicios-profesionalesfarmaceuticos\#.Xseau81S-Vg

[35] Deloitte Access Economic. Remuneration and regulation of community pharmacy - Literature review. 2016. 2020ko uztailaren 5ean sartua. Hemen eskuragarri: https://cutt.ly/1yIJYEQ

[36] Pharmaceutical Services Negotiating Committee. Pharmacy funding. 2019. 2020ko uztailaren 5ean sartua. Hemen eskuragarri: https://psnc.org.uk/ funding-and-statistics/pharmacy-funding/

[37] Pharmaceutical Services Negotiating Committee. Essential Service payments. 2019. 2020ko uztailaren 5ean sartua. Hemen eskuragarri: https:// psnc.org.uk/funding-and-statistics/funding-distribution/essential-servicepayments/

[38] Pharmaceutical Services Negotiating Committee. Advanced Service payments. 2019. 2020ko uztailaren 5ean sartua. Hemen eskuragarri: https:// psnc.org.uk/funding-and-statistics/funding-distribution/advanced-servicepayments/ 